\title{
Hemşirelerin Teknolojiye iliş̧kin Tutumları ve Etkileyen Faktörlerin Belirlenmesi
}

\author{
Hatice Saray ${ }^{1}\left[\right.$, Ayla Ünsal ${ }^{2} \odot$
}

${ }^{1}$ Kırşehir Ahi Evran Üniversitesi Eğitim ve Araştırma Hastanesi, Kırşehir, Türkiye

${ }^{2}$ Kırşehir Ahi Evran Üniversitesi Sağlık Bilimleri Fakültesi, Hemşirelik Bölümü, Kırşehir, Türkiye

Hatice Saray, Hemşire Ayla Ünsal, Prof. Dr.
İletişim:

Prof. Dr. Ayla Ünsal

Kırşehir Ahi Evran Üniversitesi Sağlık Bilimleri Fakültesi, Hemşirelik Bölümü, Kırşehir, Türkiye Tel: +903862805302

E-Posta: ay_unsal@hotmail.com
Gönderilme Tarihi : 13 Kasım 2018

Revizyon Tarihi : 150cak 2019

Kabul Tarihi : 16 Şubat 2019
ÖZET

Amaç: Gelişen teknoloji, etkili ve verimli sağık hizmeti sunma olanağını arttırmaktadır. Dolayısıyla hemşirelik uygulamalarında teknolojinin önemi sürekli olarak vurgulanmaktadır. Bu çalışma bir eğitim ve araştırma hastanesinde çalışan hemşirelerin teknolojiye ilişkin tutumlarını ve etkileyen faktörlerin belirlemesi amacıyla tanımlayıcı olarak gerçekleşmiştir.

Yöntem: Araştırma bir eğitim ve araştırma hastanesinde görev yapan 327 hemşireden gönüllü 290 hemşire $(\% 88,6)$ üzerinde yapılmıştır. Araştırma verilerinin toplanmasında literatür ışığında hazırlanmış olan anket formu ve Akbaba tarafından geliştirilen “Teknolojiye Karşı Tutum Ölçeği (TKTÖ)"kullanıImıştır. Elde edilen veriler sayı, yüzde, ortalama, standart sapma, MannWhitney U, Kruskal-Wallis ve Cronbach Alfa analizleri ile değerlendirilmiştir. Ölçeğin bu çalışmadaki Cronbach Alfası. 81'dir.

Bulgular: Hemşirelerin \%45,5'i 31-41 yaşında, \%45, 5' i lisans mezunu, \%85,2'si kadın, \%58,3'ü 6-15 yıldır görev yapmaktadır. Hemşirelerin sadece $\% 2,4^{\prime}$ ü kurumlarındaki teknolojik donanımı yetersiz bulmakta, \%99'u kısmen ve tamamen teknolojik imkan ve aletlerden faydalanmakta ve bunların \%41'i 3-5 yıldan beri teknolojiyi etkin kullanmaktadır. Hemşirelerin TKTö'den aldıkları puan ortalaması 83,43 $\pm 16,57$ bulunmuştur. Yaş, medeni durum, eğitim durumu, çalışma yılı, çalışma şekli ve kurumun yeterli teknolojik donanımları, bu konuda eğitim alma gibi durumların hemşirelerin teknolojiye ilişkin tutumlarını etkileyen bazı faktörler olduğu belirlenmiştir.

Sonuç: Yapılan çalışmanın sonucunda hemşirelerin teknolojiye ilişkin tutumlarının oldukça yüksek olduğu ve bazı değişkenlerin bu durumu etkilediği bulunmuştur.

Anahtar sözcükler: Hemşire, teknoloji, tutum, faktör

\section{NURSES' ATTITUDES TOWARDS TECHNOLOGY AND DETERMINING THE EFFECTING FACTORS}

\section{ABSTRACT}

Objectives: Emerging technology increases the ability to provide effective and efficient health care. Therefore, the importance of technology in nursing practice is constantly emphasized. This study was conducted as a descriptive study to determine the technological attitudes of nurses working in an education and research (state) hospital and factors that affect them.

Methods: The study was conducted on 290 nurses (88.6\%) with 327 nurses working in a training and research hospital. In the collection of research data, a questionnaire form prepared in the light of the literature and the "Attitudes Towards Technology Attitude" developed by Akbaba was used. The data obtained were evaluated by number, percent, mean, standard deviation, Mann-Whitney U, Kruskal-Wallis and Cronbach Alpha analyses. The Cronbach Alpha for this study is. 81.

Findings: $45.5 \%$ of nurses are $31-41$ years old, $45.5 \%$ have a bachelor's degree, $85.2 \%$ are women and $58.3 \%$ have been working for $6-15$ years. Only $2.4 \%$ of nurses find technological equipment inadequate, $99 \%$ use technological facilities and utilities partially and completely, and $41 \%$ of them use technology effectively for 3-5 years. The scale average score of the nurses was $83.43 \pm 16.57$. It has been determined that age, marital status, educational status, year of study, type of work, adequate technological equipment of the institution, education in this subject are some factors affecting nurses' attitudes towards technology.

Conclusion: It was found that nurses' attitudes towards technology were quite high and some variables affected this situation.

Keywords: Nurse, technology, attitude, factor 
B ilgi çağının etkin unsurlarından biri olan teknolojinin kullanılması birey, toplum ve meslek üyesini olaylar ve olgular karşısında daha güçlü hale getirir. Teknoloji kullanımı, yaşamı kolaylaştırmakla birlikte bireye, topluma ve meslek üyesine yeni sorumluluklar yükler. Bu sorumlulukların bilincinde olan, teknolojiyi üretip kullanabilen, teknoloji ile bütünleşen birey, toplum ve meslek üyesinin her zaman daha önde ve daha güçlü olacağı yadsınamaz bir gerçektir (1-4).

Günümüzde hızla gelişen bilişim teknolojileri sağlık teknolojisine önemli katkılar sağlamaktadır. Bu katkılar; sağlık sunumunu hızlandırma, maliyeti azaltma, sağlıklı/hasta bireyle ilgili veriyi kısa sürede elde ederek tanılama ve karar vermeyi kolaylaştırma olarak sıralanabilir. Bilişim teknolojileri hasta kayıtlarına hızlı ulaşma ve bakım gereksinimleri saptanarak uygun bakım verilmesi ve sonuçlarının izlenmesi yönüyle de bireyselleştirilmiş hemşirelik bakımı sunmada hemşireye rehber olmaktadır $(5,6)$.

Yirmi birinci yüzyılda bilim ve teknolojide yaşanan şaşırtıcı gelişmeler, sağlık sektörü başta olmak üzere her türlü sosyal, kültürel, ekonomik, siyasal vb. yaşamı etkilemiştir. Özellikle bilim ve teknolojide ileri olan ülkeler tüm alanlarda rekabet üstünlüğü istemektedir. Ayrıca çağın ileri teknolojik imkân ve olanaklarını kullanan bu toplumlar önümüzdeki yüzyılın egemen toplumları olacaklardır. Kısacası daha nitelikli yaşam olanakları ve beklentiler teknoloji kullanımını bir ayrıcalık olmaktan çıkarıp zorunlu hale getirmiştir. Bu zorunluluk sağlık alanına da yansımış olup hemşirelik alanında "yaratıcı ve yenilikçi hemşirelik", "hemşireliğin geleceği", "inovasyon”, "kaliteli hizmet", "bilişim teknolojileri", "simülasyon" vb. birçok kavramı tanımlamaya ve mesleği daha güçlü kılmaya yöneltmiştir (7).

Hemşirelik teknolojisi; sağlığı sürdürmek, geliştirmek, hastalıklardan korumak, baş edebilmek ve bakım verebilmek amacı ile bireye yardım etmede özellikle hemşireler tarafından kullanılan metot ve uygulamalar anlamına gelir. Hemşirelik kuruluşları teknolojiyi hemşirelik uygulamalarının temel yapı taşı olarak kabul eder. Ayrıca teknolojiyi etkili olarak kullanabilme, bilgi, beceri ve tutuma sahip olma hemşirelikte aranan bir niteliktir (8).

Sağlık teknolojilerini kullananların \%80'i hemşirelerdir. Hastadan veriyi toplayan, topladığı veriyi elektronik sağlık kayıtlarına aktaran hemşireler, hastaya doğrudan bakım veren, ihtiyaçlarını belirleyen, nerede, ne zaman, hangi malzemenin kullanılacağına karar veren en büyük sağlık ekibi grubu ve bilgisayar ortamına uyarlanmış sistemin birincil kullanıcılarıdır. Bu sebeplerden dolayı günümüzde profesyonel sağlık bakımı için bilgi teknolojilerini kullanarak kanıta dayalı karar verebilen hemşirelere ihtiyaç duyulmaktadır. Yeni yetişen hemşirelerin bilgi teknolojilerine ilişkin bilgi beceri ve eleştirel düşünme yeteneğine sahip olmaları, hemşirelik ve bilişim yeterliliklerini entegre edebilmeleri beklenmektedir (9).

Günümüzde sağlık bakımı ileri teknoloji içeren araç gereçlerin geliştirilmesi, yeni tanı yöntem, test ve ilaçların uygulamaya konması ile çeşitli şekillerde değişikliğe uğramıştır. Hemşirelik ise bu gelişim ve değişimlere uymak zorundadır. Bu değişimlere uyum sağlayan hemşire daha kaliteli ve kapsamlı bakım sunabilecek, sağlık ekibi içinde yeni roller kazanarak etkin bir şekilde varlığını sürdürebilecektir (10, 11). Hemşirelerin yeni roller kazanarak mesleğine daha büyük katkılar sağlaması için öncelikle teknolojiye ilişkin tutumlarının bilinmesi gerekir. Bu bilgiler ışığında bu araştırmanın amacı, hemşirelerin teknolojiye ilişkin tutumlarını ve etkileyen bazı faktörlerin belirlenmesidir.

\section{Gereç ve Yöntem}

Tanımlayıcı nitelikteki bu araştırmanın evrenini, bir eğitim ve araştırma hastanesinde görevli 327 hemşire oluşturmuştur. Araştırmada örneklem seçim yöntemine gidilmemiş evrenin tamamına ulaşılmaya çalışılmıştır. Gönüllü 290 hemşire $(\% 88,6)$ araştırma kapsamına alınmıştır. Araştırma verileri, anket formu ve "Teknolojiye Karşı Tutum Ölçeği (TKTÖ)"ile toplanmıştır. Anket formu literatür ışığında hazırlanmış olup hemşirelerin tanıtıcı özelliklerine yönelik 21 sorudan oluşmaktadır (4, 5, 9). Anket formunda yaş, cinsiyet, medeni ve eğitim durumları, çalıştığı bölüm, çalışma yılı ve şekli gibi sorular yer almaktadır. Ayrıca anket formunda hemşirelerin teknoloji kullanımına ilişkin özelliklerinin sorgulandığı 13 soru da bulunmaktadır. Hemşirelerin teknolojiye karşı tutumları ise Akbaba tarafından geliştirilen TKTÖ ile belirlenmiştir. Bu ölçek beşli likert tipindedir ve toplam 37 maddeden oluşmaktadır. Ölçeğin teknoloji benimseme, gelişme, izlem, yönetim, korku, internet, güven, karamsarlık ve kullanımı şeklinde 9 boyutu bulunmaktadır. Ölçekten alınan puanlar arttıkça teknolojiye ilişkin tutumda artma görülmektedir. Asıl ölçeğin Cronbach alpha katsayısı. 91 olarak bulunmuştur (12). Bu çalışmada ise TKTÖ'nün Cronbach alpha katsayısı. 81 olarak saptanmıştır. Verilerin toplanmasında kurumdan gerekli yazılı izin alınmıştır. Ayrıca hemşirelere araştırmanın amacı açıklanarak kendilerinden sözlü onam alınmıştır. Hemşireler ile yüz yüze görüşme tekniği kullanılarak veriler toplanmıştır. Elde edilen veriler bilgisayar ortamında sayı, yüzde, ortalama, Mann-Whitney U, Kruskal-Wallis ve Cronbach alfa analizleri ile değerlendirilmiştir. 


\section{Bulgular}

Araştırmaya katılan hemşirelerin \%45,5'i 31-41 yaşında, $\% 45,5^{\prime} \mathrm{i}$ lisans mezunu, \%85,2'si kadın, \%59'u evli, \%32,5'i dahili birimlerde, \%58,3'ü 6-15 yıldır ve \%50,7'si nöbet usulü görev yapmaktadır (Tablo 1).

Hemşirelerin \%2,4'ü kurumlarındaki teknolojik donanımı yetersiz bulurken $\% 97,6$ 'sı kısmen ve tamamen yeterli bulmaktadır. Onların \%99'u kısmen ve tamamen teknolojik imkân ve aletlerden faydalandıklarını belirmektedir. Hemşirelerin \%4,5'i 12 ve üzeri yıldır hemşirelik bakımında teknolojik cihazları etkin kullandığını belirtmiştir. Hemşirelerin teknolojik cihaz olarak en fazla bilgisayar $(\% 91,4)$ kullandıkları saptanmıştır. Hemşireler teknolojik cihazları en fazla laboratuvar bulgularını izlemek $(\% 75,9)$, bilgi edinmek $(\% 56,2)$, malzeme giriş-çıkışlarını izlemek $(\% 51,7)$ için kullandıklarını belirtmişlerdir. Hemşireler

Tablo 1. Taniticı özellikler $(n=290)$

\begin{tabular}{|c|c|c|}
\hline Tanıtıcı özellikler & Sayı & $\%$ \\
\hline \multicolumn{3}{|l|}{ Yaş } \\
\hline 19 ve altı yaş & 4 & 1,4 \\
\hline $20-30$ yaş & 126 & 43,4 \\
\hline $31-41$ yaş & 132 & 45,5 \\
\hline $42-52$ yaş & 28 & 9,7 \\
\hline \multicolumn{3}{|l|}{ Cinsiyet } \\
\hline Kadın & 247 & 85,2 \\
\hline Erkek & 43 & 14,8 \\
\hline \multicolumn{3}{|l|}{ Medeni durum } \\
\hline Evli & 171 & 59,0 \\
\hline Bekar & 119 & 41,0 \\
\hline \multicolumn{3}{|l|}{ Eğitim durumu } \\
\hline Sağlık meslek lisesi & 100 & 34,5 \\
\hline Ön lisans & 56 & 19,3 \\
\hline Lisans & 132 & 45,5 \\
\hline Yüksek lisans - doktora & 2 & 0,7 \\
\hline \multicolumn{3}{|l|}{ Çalıştığı bölüm } \\
\hline Dahili birimler & 95 & 32,5 \\
\hline Cerrahi birimler & 79 & 27,2 \\
\hline Diğer (laboratuvarlar, eğitim, palyatif vs.) & 31 & 10,7 \\
\hline Yoğun bakım & 29 & 10,1 \\
\hline Acil & 22 & 7,6 \\
\hline Poliklinik & 12 & 4,1 \\
\hline Ameliyathane & 11 & 3,8 \\
\hline Yönetim & 10 & 3,4 \\
\hline \multicolumn{3}{|l|}{ Toplam çalışma süresi } \\
\hline $1-5 \mathrm{yll}$ & 55 & 19,0 \\
\hline $6-10 \mathrm{yll}$ & 85 & 29,3 \\
\hline $11-15$ yll & 84 & 29,0 \\
\hline $16-20 \mathrm{yll}$ & 39 & 13,4 \\
\hline 21 yıl ve üzeri & 27 & 9,3 \\
\hline \multicolumn{3}{|l|}{ Şu anki çalışma şekli } \\
\hline Nöbet & 147 & 50,7 \\
\hline Vardiyalı & 36 & 12,4 \\
\hline Gündüz & 107 & 36,9 \\
\hline
\end{tabular}

teknolojinin yararları olarak en fazla zamandan tasarruf $(\% 52,4)$, çalışan verimliliğinde artış $(\% 46,9)$, çalışan memnuniyetinde artış $(\% 45,2)$ sağlayacağı ve $\% 44,1^{\prime} i$ de hemşirelik bakımında teknolojik cihazların kullanılmasının maliyeti azaltacağını ifade etmişlerdir. Hemşirelerin $\% 55,6$ 'sı hemşirelik bakımında teknolojiden faydalanırken bazen ve her zaman zorluk yaşadığını, bu zorlukların en fazla bağlantının kesilmesi $(\% 90,6)$, sistemin yavaş olması $(\% 83,8)$, hasta bakımının kişiselleştirilememesi $(\% 32,2)$ gibi zorluklar olduğunu belirtmişlerdir. Hemşirelerin \%69,3'ü kurumunda teknoloji kullanımına ilişkin hizmet içi eğitim verilmediği, \%85,9'u bu konuda eğitim almak istediği, \%73,4'ünün ise kurumun dışında teknoloji konulu eğitim programına katıldığı saptanmıştır (Tablo 2).

Tablo 2. Hemşirelerin kurumlarnndaki teknoloji kullanımına ilişkin

düşünceleri

\begin{tabular}{lcc} 
Hemşirelerin teknoloji kullanımına ilişkin özellikleri & Sayı & $\%$ \\
\hline Kurumdaki teknolojik donanımının yeterlilik düzeyi & & \\
Yeterli & 122 & 42,1 \\
Kısmen yeterli & 161 & 55,5 \\
Yetersiz & 7 & 2,4 \\
\hline Kurumun teknolojik cihazlardan faydalanma durumu & & \\
Faydalanıyor & 236 & 81,4 \\
Kısmen faydalanıyor & 51 & 17,6 \\
Faydalanmıyor & 3 & 1,0 \\
\hline Teknolojik cihazları hemşirelik bakımında kullanma süresi & & \\
2 yıl ve daha az & 29 & 10,0 \\
3-5 yıl & 119 & 41,0 \\
6-8 yıl & 93 & 32,1 \\
9-11 yıl & 36 & 12,4 \\
12 yıl ve üzeri & 13 & 4,5 \\
\hline Hasta bakımında kullanılan teknolojik cihazlar* & & \\
Bilgisayar & 265 & 91,4 \\
Şeker ve tansiyon aleti & 236 & 81,4 \\
Dijital termometre & 209 & 72,1 \\
Monitör & 181 & 62,4 \\
Çağı̈ sistemleri & 177 & 61,0 \\
Pnömotik sistemleri & 170 & 58,6 \\
Internet & 158 & 54,5 \\
Yatak başı üniteleri & 135 & 46,6 \\
Infüzyon pompası & 109 & 37,6 \\
Otomasyon sistemi & 64 & 22,1 \\
Teknolojinin en fazla kullanıldığı alanlar* & & \\
Laboratuar bulgularını izlemek & 220 & 75,9 \\
Bilgi edinmek & 163 & 56,2 \\
Malzeme giriş- Çıkışlarını izlemek & 150 & 51,7 \\
Eczaneden ilaç takibi & 117 & 40,3 \\
Hemşirelik ile ilgili kayıtları tutmak & 112 & 38,6 \\
Hasta bakımını planlamak & 107 & 36,9 \\
Personeli yönetmek ve eğitmek & 89 & 30,7 \\
Toplum sağlığını geliştirmek & 81 & 27,9 \\
Hemşirelik süreci yapmak & 80 & 27,6 \\
Araşırma yapmak & 66 & 22,8 \\
Meslektaşlarımla bilgi paylaşmak & 57 & 19,7 \\
Yönetim uygulamalarını yapmak & 38 & 13,1 \\
Hasta ve hasta yakını eğitimi yapmak & 10,7
\end{tabular}


Tablo 2 Devamı. Hemşirelerin kurumlarındaki teknoloji kullanımına ilişkin düşünceleri

\section{Teknolojiyi kullanmanın yararları*}

Zamandan tasarruf

Çalışan verimliliğinde artış

Çalışan memnuniyetinde artış

Yazılı iletişimi geliştirir

Bakım kalitesinde artış

Klinik karar vermeyi kolaylaştırma

Tekrarlayan rutin görevlerden kurtulma

Yönetici hemşirelerin hastaya verilen bakımı objektif

değerlendirmesi

Bütçede tasarruf

İstatistiksel değerlendirme ve araştırmalar için veri toplana

Depolanmış bilgilere ulaşım kolaylığı

Hemşirelik bakım planlarını standartlaşma

Hemşirelik bakımında teknolojik cihazlar kullanılması

Maliyeti azaltır

Arttırır

$28 \quad 44,1$

Etkilemez

Hemşirelik bakımında teknolojiden faydalanırken

zorluk yaşama durumu

Hic

Bazen

Her zaman

Teknolojiyi kullanırken yaşanan zorluklar $(n=161)^{\text {** }}$

Bağlantının kesilmesi

Sistemin yavaş olması

4427,3

Kişisel bilgi eksikliğime bağlı güçlükler

$43 \quad 26,7$

Her zaman ya da bazen zorlanıldığında kimden/lerden

yardım alma durumu*

Teknolojiyi iyi kullanan iş arkadaşlarından $\quad 20871,7$

Kurumun teknik personelinden $\quad 162 \quad 55,9$

Kendim çözmeye çalışıım $\quad 116 \quad 40,0$

Kurumda teknoloji kullanımı ile ilgili hizmet içi eğitim

$\begin{array}{llll}\text { Verilmedi } & 201 & 69,3\end{array}$

$\begin{array}{lll}\text { Verildi } & 89 & 30,7\end{array}$

Kurumda teknoloji kullanımı ile ilgili hizmet içi eğitimler

verilmesini isteme durumu

$\begin{array}{lrr}\text { Istiyor } & 249 & 85,9\end{array}$

İstemiyor

$41 \quad 14,1$

Kurum dışında teknoloji konulu eğitim programına

Katımad

$213 \quad 26,6$

Katılma durumu katıldı

$77 \quad 73,4$

* Yüzdeler $n=54$ üzerinden alınmıștır.

** Birden fazla yanıt verilmiştir. Yüzdeler $\mathrm{n}=290$ üzerinden alınmıştr.

** Yüzdeler $n=161$ üzerinden alınmış̦ır.

Tablo 3'de hemşirelerin TKTÖ'den aldıkları toplam puan ortalaması $83,43 \pm 16,57$ şeklindedir. Hemşireler en yüksek puanı; "Teknolojiye bağımlı olmaktan korkarım" $(3,37 \pm 1,36)$ ve "Teknolojinin insanlar arası etkileşimi azaltacağını düşünürüm" $(3,27 \pm 1,27)$, "E-posta kullanmak benim için önemli değildir" $(3,12 \pm 1,43)$, en düşük puanı ise "Teknoloji kullanan klinikleri desteklemem" $(1,65 \pm 0,59)$, "Kliniğimde yeni teknolojilerin uygulanmasından hoşlanırım" $(1,67 \pm 0,85)$ ve "Günlük işlerimde teknolojiden yararlanmaktan kaçınırım" $(1,89 \pm 1,15)$ maddelerinden almıştır.
Tablo 3. Hemşirelerin teknolojiye karşı tutum ölçeğinden aldıkları puanlar

Maddeler

$X \pm S D$

1. Günlük işlerimde teknolojiden yararlanmaktan kaçınııım.

$1,89 \pm 1,15$

2. İnsanları teknolojiyi kullanmaları için özendiririm.

$2,22 \pm 1,07$

3. Hemşireleri erken yaşlarda teknoloji ile tanıştımayı faydalı $2,03 \pm 1,23$ bulmam.

4. Bilgisayar kullanmaktan hoşlanıım.

$1,98 \pm 1,12$

5. Yeni teknolojileri öğrenmenin zaman kaybı olduğunu $2,04 \pm 1,19$ düşünürüm.

6. Meslektaşlarım ile teknoloji üzerine konuşmaktan keyif $\quad 2,34 \pm 1,11$ duyarım.

7. Teknolojideki gelişmelerin klinikteki rolümü azaltacağını $2,52 \pm 1,34$ düşünürüm.

8. Kliniğimde yeni teknolojilerin uygulanmasından hoşlanııım. $1,67 \pm 0,85$

9. Teknoloji fuarlarına katılımaktan hoşlanııım. $2,15 \pm 1,15$

10. Teknoloji ile ilgili hizmet içi eğitim programlarına katılmak $2,26 \pm 1,19$ beni rahatsı eder.

11. Teknoloji ile ilgili yayınları izlemekten zevk alırım. $2,31 \pm 1,16$

12. Hastane yönetiminde teknolojinin yarar getireceğine $2,21 \pm 1,25$ inanmam.

13. Teknoloji ile ilgili televizyon programlarını seyretmekten zevk $2,32 \pm 1,21$ alırım.

14. Teknolojinin insanları yabancılaştırdığını düşünürüm.

$2,93 \pm 1,32$

15. E-posta (e-mail) kullanmanın bir kolaylık olduğunu düşünürüm.

16. İnsanlara teknoloji fuarlarına katılmalarını öneririm.

$2,40 \pm 1,30$

17. Teknolojiye bağımlı olmaktan korkarım.

$2,44 \pm 1,15$

18. Çalıştığım personelden teknolojik gelişmelere ilişkin bilgi

$3,37 \pm 1,36$

$1,98 \pm 1,08$ almaktan hoşlanırım.

19. Teknolojinin insanlar arası etkileşimi azaltacağını düşünürüm.

$3,27 \pm 1,27$

20. Teknoloji ile ilgili konuşma yapılan ortamlarda bulunmaktan $\quad 2,48 \pm 1,18$ hoşlanırım.

21. Teknolojik gelişmeleri öğrenmek benim için fazladan bir yük $2,71 \pm 1,36$ sayilir.

22. Öğretim teknolojisinin öğrenmeyi arttırdığını düşünürüm.

23. İnsanları yeni teknolojik gelişmeler konusunda bilgilendirmekten hoşlanııım.

24. Teknolojinin insanı yerini alacağını düşünürüm.

$33 \pm 1,20$

$2,39 \pm 1,28$

25. Internette araștırma yapmaktan hoșlanııım.

$3,03 \pm 1,41$

$2,18 \pm 1,23$

26. Kendimi teknolojik gelişmeleri öğrenmek için yaşlı bulurum. 2,18 $\pm 1,39$

27. Teknoloji konusunda olușturulan gruplara katılmanın faydalı $2,65 \pm 1,44$ olacağına inanmam.

28. Teknoloji kullanan klinikleri desteklemem.

$1,65 \pm 0,59$

29. Kliniğimde yeni öğretim teknolojilerinin kullanııldı̆ını görmek $2,03 \pm 1,22$ beni mutlu eder.

30. Hemşirelerin gelişen teknolojilerden faydalanmalarını

$2,16 \pm 1,39$ kliniğim için gerekli görmem.

31. Hizmet içi eğitim programlarında teknolojiye geniş ölçüde $\quad 2,22 \pm 1,28$ yer verilmesini isterim.

32. Internette araştırma yapmayı bir kolaylık olarak görmem. $\quad 2,07 \pm 1,24$

33. Teknolojinin bilgiye ulaşmada tek yol olduğunu düşünürüm. $3,00 \pm 1,30$

34. Teknolojinin kontrolümüz altında olduğuna inanırım. $\quad 2,38 \pm 1,32$

35. İnsanlarla yeni teknolojik gelişmeler üzerine konuşmalara $\quad 2,51 \pm 1,05$ girmekten çekinirim.

36. E-posta kullanmak benim için önemli değildir. $3,12 \pm 1,43$

37. Teknoloji ile ilgili kitaplar almaktan hoşlanıım. $\quad 2,84 \pm 1,32$

TOPLAM PUAN
$2,84 \pm 1,32$
$83,43 \pm 16,57$ 
Hemşirelerin teknoloji benimseme ve gelişme ile çalışma yılı $(p<0,05)(p<0,01)$, teknoloji konulu eğitime katılma ve kurumda teknoloji konulu hizmet içi eğitim verilme durumları $(p<0,001)$ arasında istatistiksel olarak anlamlılık olduğu saptanmıştır. Teknoloji izlem ile kurumda teknoloji konulu hizmet içi eğitim verilme durumu arasında anlamlılık bulunmuştur $(p<0,01)$. Teknoloji yönetimi ile çalışma şekli arasında anlamlılık saptanmıştır $(p<0,05)$. Hemşirelerin teknoloji internet ile teknoloji konulu eğitime katılma $(p<0,05)$ ve kurumda teknoloji konulu hizmet içi eğitim verilme durumları $(p<0,001)$ arasında istatistiksel olarak anlamlılık olduğu saptanmıştır. Teknoloji karamsarlık ile çalışma şekli $(p<0,001)$, kurumun yeterli donanıma sahip olma $(p<0,001)$, kurumdaki teknolojik imkân ve aletlerden faydalanma $(p<0,05)$, teknoloji konulu eğitime katılma $(p<0,05)$ ve kurumda teknoloji konulu hizmet içi eğitim verilmesini isteme durumları $(p<0,05)$ arasında istatistiksel olarak anlamlılık saptanmıştır. Teknoloji kullanımı ile yaş $(p<0,05)$, medeni durum $(p<0,001)$, eğitim durumu $(p<0,05)$, çalışma yılı $(p<0,001)$, kurumda teknoloji konulu hizmet içi eğitim verilmesini isteme $(p<0,05)$ durumları arasında da anlamlılık bulunmuştur. Hemşirelerin ölçek toplam puanı ile çalışma yılı $(p<0,05)$, teknoloji konulu eğitime katılma $(p<0,01)$ ve kurumda teknoloji konulu hizmet içi eğitim verilme durumları $(p<0,001)$ arasında istatistiksel olarak anlamlılık belirlenmiştir (Tablo 4, 5).

Yaş, medeni durum, eğitim durumu, çalışma yılı, çalışma şekli, kurumun yeterli teknolojik donanıma sahip olma, kurumdaki teknolojik imkân ve aletlerden faydalanma, teknoloji konulu eğitime katılma, kurumda teknoloji konulu hizmet içi eğitim verilme ve bu eğitimin verilmesini isteme durumlarının hemşirelerin teknolojiye ilişkin tutumlarını etkileyen bazı faktörler olduğu belirlenmiştir. Cinsiyet ve çalışılan yerin bu konuda etkili olmadığı saptanmıştır (Tablo 4 ve 5).

Tablo 4. Hemşirelerin teknolojiye ilişkin tutumları ile tanıtıcı özelliklerinin karşılaştıııması

\begin{tabular}{lccccccc} 
Alt boyutlar & Yaş & Cinsiyet & Medeni durum & Eğitim durumu & Çalışılan yer & Çalısma yılı & Çalışma Şekli \\
\hline Teknoloji benimseme & $\boldsymbol{p}$ & $\boldsymbol{p}$ & $\boldsymbol{p}$ & $\boldsymbol{p}$ & $\boldsymbol{p}$ & $\boldsymbol{p}$ & $\mathbf{p}$ \\
Teknoloji gelişme & 0,46 & 0,68 & 0,55 & 0,30 & 0,83 & $\mathbf{0 , 0 5}$ & 0,30 \\
Teknoloji izlem & 0,20 & 0,09 & 0,09 & 0,24 & 0,11 & $\mathbf{0 , 0 1}$ & 0,06 \\
Teknoloji yönetim & 0,38 & 0,48 & 0,85 & 0,10 & 0,37 & 0,21 & 0,93 \\
Teknoloji korku & 0,14 & 0,60 & 0,65 & 0,11 & 0,69 & 0,43 & 0,05 \\
Teknoloji internet & 0,07 & 0,53 & 0,50 & 0,61 & 0,85 & 0,67 & 0,36 \\
Teknoloji güven & 0,54 & 0,19 & 0,32 & 0,89 & 0,32 & 0,62 \\
Teknoloji karamsarlık & 0,96 & 0,78 & 0,96 & 0,48 & 0,06 & 0,37 \\
Teknoloji kullanımı & 0,23 & 0,48 & 0,62 & 0,10 & 0,20 & 0,08 \\
TOPLAM PUAN & $\mathbf{0 , 0 3}$ & 0,14 & $\mathbf{0 , 0 0}$ & $\mathbf{0 , 0 3}$ & 0,08 & 0,81 \\
\end{tabular}

Tablo 5. Hemşirelerin teknolojiye ilişkin tutumları ile teknoloji kullanımına ilişkin özelliklerinin karşısştırıması

\begin{tabular}{lccccc} 
Alt boyutlar & $\begin{array}{c}\text { Kurumun yeterli } \\
\text { Teknolojik Donanıma } \\
\text { sahip olma durumu }\end{array}$ & $\begin{array}{c}\text { Kurumdaki teknolojik } \\
\text { imkân ve aletlerden } \\
\text { faydalanma durumu }\end{array}$ & $\begin{array}{c}\text { Teknoloji konulu } \\
\text { eğitime katılma } \\
\text { durumu }\end{array}$ & $\begin{array}{c}\text { Kurumda teknoloji } \\
\text { konulu hizmet içi eğitim } \\
\text { verilme durumu }\end{array}$ & $\begin{array}{c}\text { Kurumda teknoloji konulu } \\
\text { hizmet içi eğitim verilmesini } \\
\text { isteme durumu }\end{array}$ \\
\hline Teknoloji benimseme & $\mathbf{p}$ & $\mathbf{p}$ & $\mathbf{p}$ & $\mathbf{p}$ & $\mathbf{p}$ \\
Teknoloji gelişme & 0,86 & 0,99 & $\mathbf{0 , 0 0}$ & $\mathbf{0 , 0 0}$ & 0,61 \\
Teknoloji izlem & 0,24 & 0,96 & $\mathbf{0 , 0 0}$ & $\mathbf{0 , 0 0}$ & 0,14 \\
Teknoloji yönetim & 0,57 & 0,60 & 0,08 & $\mathbf{0 , 0 1}$ & 0,09 \\
Teknoloji korku & 0,83 & 0,53 & 0,70 & 0,48 & 0,09 \\
Teknoloji internet & 0,72 & 0,07 & 0,86 & 0,33 & 0,12 \\
Teknoloji güven & 0,19 & 0,42 & $\mathbf{0 , 0 2}$ & $\mathbf{0 , 0 0}$ & 0,13 \\
Teknoloji karamsarlık & 0,86 & 0,68 & 0,81 & 0,81 & 0,38 \\
Teknoloji kullanımı & $\mathbf{0 , 0 0}$ & $\mathbf{0 , 0 3}$ & $\mathbf{0 , 0 5}$ & $\mathbf{0 , 3 0}$ & $\mathbf{0 , 0 2}$ \\
TOPLAM PUAN & 0,97 & 0,33 & 0,19 & 0,80 & $\mathbf{0 , 0 4}$ \\
\end{tabular}




\section{Tartışma}

Hemşirelerin neredeyse tamamının (\%99) kısmen ve tamamen teknolojik imkan ve aletlerden faydalanıyor olma$\mathrm{sI}$, kurum ve çalışanlar için oldukça sevindirici bir sonuçtur. Bu kurumdaki sonuçların pek çok sağlık kuruluşunda da yaşanması istenmektedir. Yalduz'un (2009) yaptığı çalışmada da cerrahi hemşirelerinin \%71,2'sinin teknolojik donanımdan yararlandığı saptanmıştır. Bu sonuçlar hemşirelerin teknolojiyi kullanma konusunda istekli olduğunu göstermektedir (13).

Sağlık Bakanlığı 1991'de Dünya Bankası işbirliği ile başlatılan birinci ve 1995 'de başlatılan ikinci sağlık projeleri kapsamında Sağlık Enformasyon Sistemleri Projesi ile Hastane Bilgi Yönetim Sistemleri çalışmalarını başlatmıştır (14). 12 ve üzeri yıldır teknolojik cihaz kullanan hemşirelerin $\% 4,5$ düzeyinde olması göz önüne alındığında hemşirelerin iş yerlerinde teknolojiyi kullanmalarının gecikmiş olduğu düşünülmektedir. Bunun sebepleri kurumsal yetersizlikler, hemşirelerin bilgi eksikliği, isteksizliği gibi pek çok faktör olabilir.

Bu araştırmada hemşirelerin teknolojik cihaz olarak en fazla bilgisayar kullandığı bulunmuştur. Türkoğlu'nun yaptığı çalışmada da (2010) hemşirelerin evlerinden sonra en çok bilgisayar kullandıkları yerin iş yerleri olduğu belirlenmiştir (15). Buna benzer olarak Kaya ve arkadaşlarının (2008) yaptığı çalışmada da iş yerlerinde bilgisayar kullanma düzeyi yüksek bulunmuştur (16). Ayrıca bu araştırmada dijital şeker, tansiyon aleti ve dijital termometrenin de çok kullanıldığı belirlenmiştir. Aktaş ve arkadaşlarının (2017) yoğun bakım hemşireleri üzerinde konu ilgili yaptıkları çalışmada yoğun bakım ünitelerinde de ilk sıralarda dijital tansiyon aleti ve termometre kullandığı saptanmıştır (17). Ayrıca hemşireler en çok yaşam bulguları ve glikoz seviyesini ölçtüğü için bu durum beklenen bir sonuçtur.

Yapılan bazı çalışmalarda aynı bu araştırmada olduğu gibi hemşirelerin en fazla laboratuvar sonuçlarını ve malzeme giriş çıkışlarını izlemek için teknolojiyi kullandığı saptanmıştır $(15,16,18)$.

Bu araştırmada hemşireler, teknolojinin bazı yararlarından söz etmişlerdir. Benzer şekilde Aktaş ve arkadaşlarının (2017), Hübner ve arkadaşlarının (2010) ve Yalduz'un (2009) çalışmalarında da teknolojinin hasta bakım kalitesini arttırdığı ve kolaylıklar sağladığı belirtilmiştir $(13,17,19)$.

Hemşirelerin bu araştırmada bahsettikleri teknoloji kullanımındaki zorluklar yapılan çalışma sonuçlarında da bahsedilmiştir $(15,20,21)$. Bu durum kurumların bağlantının kesilmesi ve sistemin yavaş olması konusunda daha etkili önlemler alması gerektiğini düşündürmektedir. Bu araştırmadaki hemşireler zorluklar konusunda \%71,7'si teknolojiyi iyi kullanan iş arkadaşlarından yardım aldığını ifade etmiştir.

Bu araştırma ile benzer şekilde Değirmen ve arkadaşlarının (2006) ve Erdemir ve arkadaşlarının (2005) çalışmalarındaki hemşirelerin de kurumlarından teknoloji konusunda hizmet içi eğitim almak istedikleri saptanmıştır $(18,22)$. Bu durumda kurumların hizmet içi eğitim programlarına teknoloji ile ilgili konular eklemelerinin önemli olacağı düşünülmektedir. Yine benzer şekilde Aktaş ve arkadaşlarının (2017) yaptığı çalışmada eğitime katılma düzeyi \%89,9 olarak bulunmuştur (17). Fakat Yalduz'un (2009) yaptığı çalışmada ise hemşirelerin \%32,7'sinin teknoloji ile ilgili eğitimlere katıldığı saptanmıştır (13). Bu araştırma hastanede çalışan tüm hemşireler üzerinde yapılmasına rağmen Yalduz'un çalışması sadece cerrahi hemşireleri üzerinde yapılmıştır (13). Ayrıca bu araştırmanın, sözü edilen çalışmaya göre yaklaşık 10 yıl kadar sonra yapılmış olması sonucu etkilemiş olabilir.

Hemşirelerin TKTÖ'den aldıkların toplam puanın yüksek olması onların teknolojiye ilişkin tutumlarının yüksek olduğunu göstermektedir. Bu durum sağlık bakım kalitesi açısından sevindirici bir sonuçtur. Bu araştırmada hemşirelerin TKTÖ'nin maddelerinden aldıkları en yüksek ve en düşük puanlar ile Yalduz'un (2009) yaptığı çalışmanın puanları arasında farklııklar bulunmaktadır (13). Bu durum her iki çalışmanın örneklem grupları ve yılları arasındaki farklılıktan kaynaklanıyor olabilir.

$\mathrm{Bu}$ araştırmada hemşirelerin teknoloji kullanımı konusunda yaşın etkili olduğu saptanmıştır. İspir ve arkadaşlarının (2007) öğretmenler üzerinde yaptığı araştırmada bireylerin yaşlara ve teknolojiye ilişkin tutum ölçeğinden aldıkları puanlara bakıldığında anlamlı bir fark olduğu görülmüştür (23). Kısa'nın (2006) hemşire öğretim elemanları üzerinde yaptığı çalışmasında da teknolojiyi benimseme boyutunda yaş grubunda çok ileri derecede anlamlılık saptanmıştır (24). Ayrıca bu bulguya benzer şekilde hemşirelerin hastanelerde kullandıkları elektronik kayıt sistemleri ile yaş ve çalışma yılları arasında anlamlılık olduğu saptanmıştır (25).

Bu araştırmada Aktaş ve arkadaşlarının (2017) ve Yalduz'un (2009) yaptığı çalışmada olduğu gibi cinsiyetin teknoloji kullanımında etkili olmadığı belirlenmiştir $(13,17)$. Ayrıca 
bu ve Yalduz'un (2009) çalışmalarında teknoloji konulu eğitim/kurs/kongreye katılmanın teknoloji kullanımını etkilediği saptanmıştır (13).

\section{Sonuç ve Öneriler}

Hemşirelerin teknolojiye ilişkin tutumlarını belirlemek amacıyla yapılan bu çalışmada, hemşirelerin teknolojiye ilişkin tutumlarının oldukça yüksek olduğu ve bazı faktörlerin bu durumu etkilediği saptanmıştır. Bu faktörlerin yaş, medeni durum, eğitim durumu, çalışma yılı, çalışma şekli, kurumun yeterli teknolojik donanıma sahip olma, kurumdaki teknolojik imkan ve aletlerden faydalanma, teknoloji

\section{Kaynaklar}

1. Kaya H. Hemşirelik Eğitiminde Değişimler ve Gelecek. I Ü F N Hem Derg 2003;13:73-9.

2. Taşocak G. Eğitimde süreklilik. Ulusal Hemşirelik ve Ebelik Mesleğinin Boyutları Sempozyumu, Samsun, 2002.

3. Bayık A. Yirmi birinci yüzyıl hemşireliği hemşirelik eğitimi ve hemşirelik eğiticilerinin rolleri için nasıl bir değişim? I. Uluslararası V. Ulusal Hemşirelik Eğitimi Kongre Kitabı, Nevşehir, 2001.

4. Dinç L. Bilgisayarın Hemşirelik Eğitimi ve Hizmetlerindeki Yeri. Hacettepe Üniversitesi Hemşirelik Yüksekokulu Derg 1995;2:47-50.

5. Ay F. Uluslararası Elektronik Hasta Kayıt Sistemleri, Hemşirelik Uygulamaları ve Bilgisayar İlişkisi. Gülhane Tıp Derg 2009;51:131-6. http://cms.galenos.com.tr/Uploads/Article_33316/GMJ-51-131-En.pdf

6. Başar A, Delice ST, İlhan MN, Ergün MA, Soncul H. Hemşirelik Hizmetlerinde Bilgisayar Kullanımı - Gazi Üniversitesi Tıp Fakültesi Örneği. Bilişim Teknolojileri Derg 2008;1:43-6.

7. Bodur G, Kaya H. Hemşireliğin Geleceği: 2050'li Yıllar. I Ü F N Hem Derg 2015;23:166-73.

8. Aştı T. Bakım teknolojisinde yenilikler. Kasım Paşa Deniz Hastanesi Bilimsel Toplantı Programı, 2003.

9. Softa HK, Akduran F, Akyazı E. Hemşirelerin Bilgisayar Kullanımlarına Yönelik Tutumlarının Değerlendirilmesi. Gümüşhane Üniversitesi Sağlık Bilimleri Derg 2014;3:845-59. http://static.dergipark.org.tr/ article-download/fd9a/405a/df19/imp-JA78YE33FZ-0.pdf?

10. Potter P, Parry AG. Fundamentals of Nursing. Philadelphia: Mosby Year Book Inc.; 1997.

11. Sandelowski M. Toward a Theory of Technology Dependency. Nurs Outlook 1993;41:36-42.

12. Akbaba Altun S. Okul Yöneticilerinin Teknolojiye Karşı Tutumlarının İncelenmesi. Çağdaş Eğitim Derg 2002;286:8-14.

13. Yalduz N. Cerrahi Hemşirelerinin Teknolojiye İlişkin Tutumları. Marmara Üniversitesi Sağlık Bilimleri Enstitüsü Yüksek Lisans Tezi. İstanbul; 2009;s14-s44.

14. Ak B. Türkiye'de Sağlık Bilişimi, Bir Kişisel Değerlendirme ve Uluslararası Bir Başarı Öyküsü: CorTTex. Akademik Bilişim'09 - XI. Akademik Bilişim Konferansı Bildirileri, Harran Üniversitesi, Şanlıurfa, 2009, 333-41. konulu eğitime katılma, kurumda teknoloji konulu hizmet içi eğitim verilme ve bu eğitimin verilmesini isteme durumları olduğu belirlenmiştir.

\section{Bu araştırmanın sonucunda;}

- Kurum içerisindeki hizmet içi eğitim programlarına teknoloji ile ilgili konuların eklenmesi ve hemşirelerin bu eğitimlere katılımına yönelik teşvikin sağlanması,

- Benzer araştırmaların farklı hastanelerde ve farklı örneklem gruplarında yapılması, bunun sonuçları ile karşılaştııılması ve elde edilen sonuçların uygulamaya aktarılması önerilebilir.

15. Türkoğlu J. Hemşirelerin Bilişim Teknolojisini Kullanımı ve Etkileyen Faktörler. Marmara Üniversitesi Sağlık Bilimleri Enstitüsü Hemşirelikte Yönetim Anabilim Dalı Yüksek Lisans Tezi, İstanbul, 2010.

16. Kaya N, Aştı T, Kaya H, Kaçar G. Hemşirelerin Bilgisayar Kullanımına İlişkin Görüşlerinin Belirlenmesi. İ. Ü. F. N. Hemşirelik Yüksekokulu Dergisi 2008;16:83-9.

17. Yaman Aktaş $Y$, Koraș $K$, Karabulut N. Yoğun Bakım Hemșirelerinin Teknolojiye İlişkin Tutumları. Hacettepe Üniversitesi Hemşirelik Fakültesi Derg 2017;4:36-48. http://static.dergipark.org.tr/articledownload/2614/c0a8/c935/599d5ab4dd913.pdf?

18. Erdemir F, Hanoğlu Z, Akman A. Hemşirelerin Bilgisayar ve İnternet Kullanma Durumu ve Hemşirelikte Bilgisayar Kullanımının Değerine İlişkin Görüşleri, 2. Ulusal Tıp Bilişimi Kongresi, Antalya, 2005.

19. Hübner U, Ammenwerth E, Flemming D, Schaubmayr C, Sellemann B. IT Adoption of Clinical Information Systems in Austrian and German Hospitals: Results of a Comparative Survey with a Focus on Nursing. BMC Med Inform Decis Mak 2010;10:8. [CrossRef]

20. Lee TT. Nursing Information: Users'experience of a System in Taiwan One Year after Its Implementation. J Clin Nurs 2008;17:763-71. [CrossRef]

21. Gabr H. The Effect of Computerized Patient Record on Nurses' Time Spent on Documentation in Inpatient Units. Int J Acad Res 2010;2:108-20.

22. Değirmen N, Yeter K, Çalık E. Cerrahi Kliniklerinde Sağlık Personelinin Bilgisayar Kullanma Durumlarının Belirlenmesi. Dumlupınar Üniversitesi Akademik Bilişim'07-IX. Akademik Bilişim Konferansı Bildirileri, Dumlupınar Üniversitesi, Kütahya, 2007;533-7.

23. İspir $E$, Furkan $H$, Çitil M. Lise ve Fen Grubu Öğretmenlerinin Teknolojiye İlişkin Tutumları - Kahramanmaraş Örneği. Erzincan Eğitim Fakültesi Derg 2007;9:63-72. http://static.dergipark.org.tr/ article-download/imported/1006000698/1006001210.pdf?

24. Kısa B, Kaya H. Hemşire Öğretim Elemanlarının Teknolojiye Illişkin Tutumları. The Turkish Online Journal of Educational Technology-TOJET 2006;5:77-84. http://www.tojet.net/articles/ v5i2/5211.pdf

25. Eriş H. Hemşirelerin Hastanelerde Kullandıkları Elektronik Tıbbi Kayıtlar Hakkındaki Görüşleri: Şanlıurfa Örneği. Sağlık Akademisyenleri Derg 2016:3:93-9. [CrossRef] 